\title{
INCONGRUENCIA CONSTITUCIONAL EN EL COBRO DEL IMPUESTO DE DIVISIÓN SOBRE BIENES INMUEBLES DE DOMINIO PÚBLICO
}

\author{
Incongruent To The Mexican Contitution The Payment \\ Division Tax For State Property Of Public Domain
}

Alberto GASCA TOVAR*

\section{Sumario:}

I. Introducción II. Bienes de derecho público III. Base de las contribuciones y exenciones $I V$. Impuestos municipales $V$. Incongruencia en la interpretación conforme a nuestra Constitución o inconstitucionalidad de los impuestos municipales sobre bienes inmuebles de servicios público VI. A manera de conclusión

Resumen: El Estado, para el cumplimiento de sus atribuciones y la prestación de los servicios públicos, requiere de bienes inmuebles, que conforme a nuestra constitución están exentos de pagar contribuciones municipales, estatales y federales. La adquisición por donación de inmuebles destinados a la prestación de un servicio público, se interpreta cobrar el impuesto de división al donatario, a pesar de su aportación gratuita al Estado que destinará dicho bien al dominio público. La interpretación estricta en materia fiscal respecto de la exenciones y la falta de congruencia de la ley respecto de la Constitución que le faculta el cobro de impuestos inmobiliarios a los municipios, en que le expresa los casos en que se tendran por exentos estos, hace considerar una adición a la ley para evitar su inconstitucionalidad.

Palabras clave: Contribuciones, Impuestos, Interpretación, Exención, Dominio público, Inconstitucionalidad

Abstract: The State, for compliance of its attributions of the provision of public services, requires State property, which according to the Mexican Constitution is exempt from municipal, State an Federal taxes. However, in the acquisition by donation of real state property intended for public service, it is interpreted to change a division tax to the donor despite its gratuitous donation to the State and that the property will be allocate to the public domain. The strict interpretation in the tax matters respect to the exempt and

* Licenciado en Derecho por la otrora Facultad de Derecho de la Universidad de Guanajuato, egresado de la especialidad en Notario Público de la División de Derecho, Política y Gobierno campus Guanajuato de la Universidad de Guanajuato. 
the lack of consistency in the Constitution whichs authorizes payment of the property taxes to the municipalities, as well as cases considered for exemption, makes consider an addition to the law to avoid it is unconstitutionality.

Keywords: Contribution, Taxes, Interpretation, Exempt, Public domain, Unconstitutionality

\section{Introducción}

El Estado justifica su existencia con acciones que beneficien directamene a la población, requiriendo de bienes materiales y recursos para lograrlo. Existe una relación directa y razón de ser, entre lo que percibe por medio de la recaudación de impuestos y las acciones en la prestación de servicios públicos. En coherencia, los bienes de dominio público del estado, están destinados a la prestación directa de servicios públicos y es de interés general su conservación, por lo que se establece en nuestra constitución general, la no causación de impuestos inmobliarios de bienes de la Federación, los Estados y los municipios, que estén destinados en forma directa a estos fines de interés común.

Así nuestra Carta Magna, como punto de partida de nuestro sistema jurídico, le otorga facultades a los municipios para el cobro de impuestos en materia inmobiliaria, expresando los valores y lineamientos para su legislación local, con la determinación de las contribuciones e impuestos sobre la tenencia inmobiliaria, cambios de propietarios, fraccionamientos en su area geográfica y la regulación de su espacio urbano, siguiendo los principios de legalidad y proporcionalidad. Por lo que toda adquisición de inmuebles se debe ajustar a los lineamientos que marca nuestra Ley de Hacienda para los municipios del Estado de Guanajuato, incluyendo las donaciones que particulares realizan a favor del Estado para el establecimiento de un servicio público, encontrándose exento del pago del impuesto de adquisición, pero no del impuesto de división, requiriéndole de pago al particular donante para bienes del dominio público.

En cuando al impuesto predial y al impuesto de adquisición de inmuebles, nuestra Ley de Hacienda para los municipios del Estado establece conforme, al mandato constitucional, la exención de su pago a los bienes de dominio público a los tres ordenes de gobierno. No así del impuesto de división, que establece causales para su no pago. Esto se confronta con la norma de derecho fiscal que establece que en cuanto a cargas a los particulares y a las exenciones se aplicará la ley de manera estricta, es decir sin permitirnos aplicar los métodos de interpretación jurídica.

Por lo que al tener establecido que solamente se puede tomar como exento lo que la ley permite, maxime que toda cuenta municipal es revisada minuciosamente con el fin de evitar cualquier desviación que afecte su hacienda, es necesario que se establezca en forma expresa la exención para el caso de bienes destinados al dominio público, con su respectiva modificación a la ley de la materia. Lo que conlleva, la formalización de la propiedad del estado que proviene de particulares para destinarse a bienes para la prestación de un servicio público. 


\section{Bienes de derecho público}

El Estado como entidad soberana y sujeto a atribuciones de derecho público requiere contar con los bienes necesarios para el cumplimiento de sus obligaciones de servicio público. Por lo que el artículo 27 Constitucional establece la base de nuestro sistema, constituyendo la titularidad de la propiedad originaria a la Nación ${ }^{1}$. Arce y Cervantes ${ }^{2}$ nos indican que la interpretación debe hacerse consierando la razón histórica, citando a Pastor Rovaix, presidente de la comisión que redactó el artículo 27, explica que Durante la dominación española, todas las tierras pertenecían a la Corona de España, y al momento de la Independencia estos derechos pasaron a la nueva Nación Independiente; agregando que la conquista es un medio de adquisición reconocido por el derecho internacional público ${ }^{3}$. Difiriendo Reyes Tayabas $^{4}$ dice que, no implica divinidad ni sucesión de entidades políticas, si no solo una manifestación de soberanía con la aparición del nuevo Estado a través del Constituyente. En este artículo constitucional, se deja plasmado su aspecto social al establecer la base para la expropiación y la facultadad de dictar modalidades conforme al interés público, limitando el uso, disfrute y disposición total de la propiedad. Este primer párrafo nos otorga dos vertientes, una en el aspecto de Estado como ente conformado por territorio, población y gobierno, que establece la soberanía que tiene la nación sobre su territorio estableciendo sus limites, y la otra los que establece su dominio directo sobre los recursos naturales de la plataforma continental y los zócalos submarinos de las islas, de todos los minerales, el petróleo y los carburos, el espacio aéreo y las aguas de los mares e interiores y los baldios nacionales, con su respectiva protección de ser inalienables e imprescriptibles.

Para Arce y Cervantes hay dos formas de usar la propiedad, la individualista y la comunitaria, la primera cuando el particular se aprovecha en forma personal para su provecho, y la segunda cuando el uso de los bienes privados es para su beneficio además de que se subordina al bien común 5 . Por lo que en su párrafo tercero del 27 constitucional se establece la facultad de la Nación de imponer modalidades que dicte el interés público, pudiendo limitar o restringir en sus prerrogativas de: usar, disfrutar y disponer ${ }^{6}$.

Como resultado de una herencia romana, se clasifican los bienes conforme a la persona que los detenta en bienes particulares y bienes de dominio público, estos últimos los tiene como titular el Estado. Siendo necesaria esta división para identificar las reglas de derecho que les son aplicables ${ }^{7}$. Considerando al Estado como una persona moral de derecho

Artículo 27 de la Constitución Política de los Estados Unidos Mexicanos establece La propiedad de las tierras y aguas comprendidas dentro de los límites del territorio nacional, corresponden originálmente a la Nación, la cual ha tenido y tiene el derecho de transmitir el dominio de ellas a los particulares, constituyendo la propiedad privada.

2 Arcer y Cervantes, José (2008), De los Bienes, $7^{\mathrm{a}}$ ed. México, Porrúa, p. 114.

${ }^{3}$ Existe la llamada bula Alejandrina o de partición, mediante la cual el Papa divide los territorios de América entre España Y Portugal, expedida el 4 de mayo de 1493. Considerando por algunos como la confirmación de la soberanía y dominio de los reyes de España y por otros como la dimisión de controversia.

${ }^{4}$ Reyes Tayabas, Jorge (1993), Derecho Constitucional aplicado a la Especialización en Amparo, $2^{\mathrm{a}}$ ed. México, Themis, p. 304.

5 Ibídem, p. 46.

6 Rojas Caballero, Ariel Alberto (2009), Las Garantias Individuales en Mexico, $4^{\mathrm{a}}$ ed. México, Porrúa, p. 223. El régimen jurídico de los bienes inmuebles del Estado es de carácter público y privado, por ser bienes de interés común se le da una protección especial para mantener la finalidad de su existencia, frente a los particulares y los propios funcionarios públicos. 
público, con su atributo de tener un patrimonio. Gabino Fraga nos dice que El conjunto de bienes materiales que de modo directo o indirecto sirven al Estado para realizar sus atribuciones constituyen el dominio o patrimonio del propio Estado ${ }^{8}$. Que al tener tres órdenes de gobierno: la federación, los estados y sus municipios ${ }^{9}$, son estos quienes ejercen el dominio sobre los bienes que les pertenecen. Galindo Garfias nos indica que el poder público ejerce el dominio o señorío sobre la cosa, relacionándolo con la idea de soberanía frente a la de propiedad que solo tiene la pertenencia ${ }^{10}$.

En su denominación es coincidente nuestra Constitución Política del Estado de Guanajuato, Código Civil para el Estado de Guanajuato ${ }^{11}$ y la Ley del Patrimonio Inmobiliario del Estado ${ }^{12}$, al dividir los bienes, en bienes particulares y de dominio del poder público, siendo estos últimos los pertenecientes a la federación, a los estados o a los municipios. Que para el caso de nuestro estado es la Ley del Patrimonio Inmobiliario del Estado, la que establece su régimen, protección y regulación de su uso y destino, con su división entre bienes de dominio público y bienes de dominio privado, determinando para los primero el goce de ser inalienables e imprescriptibles.

En nuestra Ley del Patrimonio del Estado se les define como: Artículo 13.- Los bienes inmuebles del dominio público son todos aquellos que le pertenecen al Estado, que de forma directa o indirecta están afectados a una colectividad y que no son susceptibles de posesión o propiedad particular. Siguiendo a Delgadillo y Lucero nos refiere que [...] el dominio público es el derecho de propiedad que el Estado tiene sobre determinados bienes, sometidos a un régimen de derecho público $[\ldots]^{13}$, y le agregan como elemento sustantivo que están afectos a un propósito de interés colectivo, por lo que tienen la característica de inalienables e imprescriptibles. Exponiendo la naturaleza jurídica en cuatro teorías: a) De la soberanía, deja a estos bienes sin dueño y al estado como soberano ejerce el poder de administrador y vigilante únicamente, sin personalidad para su protección;

${ }^{8}$ Fraga, Gabino (2003), Derecho Administrativo, 43ª ed. México, Porrúa, p. 345.

9 Nuestro Código Civil en el Articulo 24 nos dice Son Personas Morales: I.- La Nación, las Entidades Federativas y los Municipios.

${ }^{10}$ Galindo Garfias, Ignacio (1993), Código Civil para el Distrito Federal en materia común y para toda la República en materia federal comentado, $2^{\mathrm{a}}$ ed. México, Grupo Editorial Miguel Ángel Porrúa-UNAM, t. II, p. 14.

${ }^{11}$ Artículo 805 del Código Civil para el Estado de Guanajuato Los bienes son del dominio del poder público o de propiedad de los particulares.

${ }^{12}$ Nuestra Constitución local en su Título Sexto del Patrimonio y Hacienda Pública del Estado nos dice: ARTÍCULO 96.- Los bienes que integran el patrimonio del Estado son:

I.- De dominio público; $y$,

II.- De dominio privado.

ARTÍCULO 97.- Son bienes de dominio público:

I.- Los de uso común;

II.- Los destinados por el Gobierno del Estado a los servicios públicos;

III.- Los inmuebles y muebles de valor histórico y cultural que le pertenezcan; y

IV.- Los demás que señalen las Leyes respectivas.

ARTÍCULO 98.- Son bienes de dominio privado del Estado los que ingresen a su patrimonio, no comprendidos en el artículo anterior.

${ }^{13}$ Delgadillo Gutiérrez, Luis Humberto y Lucero Espinosa, Manuel (2008), Compendio de Derecho Administrativo, segundo curso, $4^{\mathrm{a}}$ ed. México, Porrúa, p. 69. 
b) De la propiedad del pueblo, el pueblo es el dueño y el estado solo es administrador y representante, con su origen histórico pero con la dificultad que la anterior de falta de personalidad para su protección; c) De la Propiedad privada del Estado, le dá el trato civilista de particular al Estado que en nuestro sistema jurídico pertenece a normativa de derecho público por tener un interés colectivo en su protección; d) De la propiedad pública del Estado, es la que indica que la propiedad se traslada al ámbito administrativo creando un régimen propio orientado a su destino, teoría aceptada por nuestro sistema ${ }^{14}$.

Por lo que basta que un bien este destinado a su servicios público o de uso común, para que los derechos sean sujetos de la protección de no poder apropiarse por particulares, por estar fuera del comercio, al ser inalienables e imprescriptibles, con circunstancias de hecho sin que sean necesarias formalizaciones de incorporación a padrón alguno para que sean consideradas de dominio público ${ }^{15}$.

\section{Base de las contribuciones y exenciones}

Es de observarse primeramente que el Estado tiene como finalidad el beneficio social, conforme lo establece el artículo 39 Constitucional $^{16}$, por lo que las atribuciones y acciones de gobierno deben de estar establecidas en ley y en concordancia con la propia Constitución.

El pueblo en ejercico de su soberanía establece la forma de gobierno y de vivir, imponiendo al Estado como función y razón de ser la satisfacción de las necesidades comunes. Así Martínez López establece como punto de partida, "Esa finalidad, de bienestar del pueblo, impuesta al Estado Mexicano en el articulo 39 de la Constitución Federal, es la meta de la 'Politica Fiscal , [... ${ }^{17}$; entendiendo esta como el estudio que realiza el Estado, en el que determina el presupuesto de gastos de su función y su correlativa fijación de impuestos, basándose en la experiencia de necesidades, proyectos, estadísticas, equilibrio de la económia y colaboración de su sector productivo y social.

El Estado, para el seguimiento de sus acciones que les son encomendadas, requiere de recursos de quienes lo han establecido y beneficiarios de los servicios, por lo que el artículo 31 fracción IV de la Constitución establece la obligación de contribuir con los gastos públicos de la Federación, asi como del estado y del Municipio en que residan, de manera equitativa y proporcional que determinen las leyes. Por lo que las contribuciones deberán de pagarse a los tres ordenes de gobierno, llamados sujetos activos. Existiendo la coordinación fiscal para que conforme a las facultades de la federación se establezcan los rubros por los que las legislaciones funden los que correspondan a cada cual, encontrándonos en algunos casos la llamada concurrencia tributaria, cuando una persona, llamada sujeto

\footnotetext{
${ }^{14}$ Ibídem, pág 70 y 71.

${ }^{15}$ El agregar elementos como inembargable, aun y que sea una consecuencia de inalienable y la protección que otorga el Codigo de Procedimientos Civiles para el Estado de Guanajuato a estos bienes en su segundo párrafo del articulo $8^{\circ}$, viene a apoyar en la comprensión de la protección como lo hace SANCHEZ Gómez, Narciso (2015), Segundo Curso de Derecho Administrativo, $5^{\mathrm{a}}$ ed. México, Porrúa, p. 68.

${ }^{16}$ Artículo 39 Constitución Política de los Estados Unidos Mexicanos La soberanía nacional radica esencial y originálmente en el pueblo. Todo poder público dimana del pueblo y se instituye para beneficio de este.

${ }^{17}$ Martínez López, Luis (1959), Derecho Fiscal Mexicano, México, Porrúa, p. 30.
} 
pasivo, tiene que pagar a diferentes autoridades fiscales por el mismo hecho ${ }^{18}$. Mabarak Cerecedo nos refiere que la proporcionalidad y la equidad en las contribuciones, dimanan de los principios de Adam Smith en su libro La Riqueza de las Naciones, bajo el principio de justicia en la imposición, que refiere que las contribuciones deben de ser conforme a la capacidad económica del gobernado, además de que deben de ser producto de normas generales que graven de la misma forma a los que se encuentren en igualdad de condiciones $^{19}$. Nuestra jurisprudencia refiere las características a cuidar por la ley cuando nos dice "El impuesto requiere ser proporcional y esa proporción, para ser justa, se fundará, en primer término, en el ingreso del contribuyente, punto de partida para aquilatar su capacidad contributiva y poder significarse que si aquél obtiene mayores ingresos, más alto tendrá que ser el impuesto que llegará a satisfacerse $[\ldots]^{20}$.

El municipio libre como ente administrativo con personalidad jurídica, con patrimonio y con libertad en la administración de sus recursos, con facultades expresas para el cobro de las contribuciones sobre la propiedad inmobiliaria ${ }^{21}$, está tambien facultado para establecer los elementos para la imposición de las contribuciones municipales conforme a la Constituciòn del Estado ${ }^{22}$, existiendo una potestad tribuntaria compartida entre el Estado y los municipios para su fijación ${ }^{23}$.

Es en la ley en donde se configura la estructura del tributo y se especifica la conducta a la que se atribuye el carácter generador de la obligación fiscal, conforme al principio de legalidad. La obligación tributaria se estructura como cualquier otra obligación, es decir como un derecho de crédito y de una correlativa obligación.

La norma de las contribuciones municipales es la Ley de Hacienda para los Municipios del Estado de Guanajuato, que nos refiere los tipos de ingresos, sujetos, obligaciones, nacimiento de créditos fiscales, tipos de impuestos, derechos, contribuciones especiales, productos y aprovechamientos, que en conjunto a la ley de ingresos anual que contiene las tarifas y tasas para cobro, hacen posible su implementación legal.

Respecto a las exenciones a los impuestos, es decir la exclusión de forma particular de no pagar un impuesto, la forma de excepción a lo establecido en el artículo 28 de nuestra

${ }^{18}$ Mabarak Cerecedo, Doricela (2007), Derecho Financiero Público, $3^{\mathrm{a}}$ ed. México, McGRaw-Hill Interamericana, p. 86 y 87.

${ }^{19}$ Ibídem, p. 72.

${ }^{20}$ Tesis 641, Semanario Judicial de la Federación y su Gaceta, séptima época, Tomo I, p. 1787.

${ }^{21}$ Artículo 115 fracción IV,

Los municipios administrarán libremente su hacienda, la cual se formará de los rendimientos de los bienes que les pertenezcan, así como de las contribuciones y otros ingresos que las legislaturas establezcan a su favor, y en todo caso: a) Percibirán las contribuciones, incluyendo tasas adicionales, que establezcan los Estados sobre la propiedad inmobiliaria, de su fraccionamiento, división, consolidación, traslación y mejora así como las que tengan por base el cambio de valor de los inmuebles."

${ }^{22}$ Artículo 117.- A los Ayuntamientos compete: VIII.- Proponer al Congreso del Estado, las cuotas y tarifas aplicables a impuestos, derechos, contribuciones de mejoras y tablas de valores unitarios del suelo y construcciones que sirvan de base para el cobro de las contribuciones sobre la propiedad inmobiliaria, en los términos que señale la Ley.

${ }^{23}$ Tesis $1^{a} \mathrm{CXI} / 2010$, Semanario Judicial de la Federación y su Gaceta, $9^{\mathrm{a}}$ época, tomo XXXII, noviembre de 2010, pág. 1213. HACIENDA MUNICIPAL. PRINCIPIOS, DERECHOS Y FACULTADES EN ESA MATERIA, PREVISTOS EN EL ARTÍCULO 115 FRACCIÓN IV DE LA CONSTITUCIÓN POLÍTICA DE LOS ESTADOS UNIDOS MEXICANOS. 
Constitución General que dice En los Estados Unidos Mexicanos quedan prohibidos los monopolios, las practivas monopólicas, los estancos y las exenciones de impuestos en los términos y condiciones que fijan las leyes, pareciendo una contradicción al prohibir en los términos que fijan les leyes. El maestro Luis Martínez nos dice que las exenciones están fundadas en la ausencia de capacidad tributaria o en alguna circunstancia de orden público que justifique la liberación ${ }^{24}$. Por lo que podemos decir que como todo lo tribuntario debe de estar en ley, nos remite a los términos y condiciones que se establezcan, que por circunstancias especiales sea necesario dejar de cobrar el impuesto, siendo la forma de aclarar o delimitar a quien va dirigido el gravamen y quienes por circunstancias particulares no les aplica, por lo que podría considerarse una técnica legislativa para delimitar el verdadero sentido de una norma general. Siguiendo a Mabarak Cerecedo nos dice no se está frente a una prohibición absoluta sino relativa, porque para hacerla efectiva es necesario que las leyes fiscales complementen, den las condiciones y aporten los términos mediante los cuales pueda hacerse efectiva $[\ldots]^{25}$, debiendo ser las leyes fiscales cuidadosas de cumplir el principio de generalidad necesario para la expedición de leyes, dejando fuera la tentación a nuestras autoridades de exentar a personas en particular, y asi lo interpreta la Suprema Corte bajo el rubro Principio de generalidad tributaria. Su alcance en relación con las excenciones ${ }^{26}$ con lo que corroboramos que se prohíbe a nivel individual pero no las de carácter general en lo subjetivo u objetivo.

Nos encontramos términos como no pago, tasa cero y la enumeración de los casos que se encuentra exento determinado impuesto, así como las exenciones temporales que por circunstancias especiales es necesario establecer para proteger o aumentar la productividad de algún sector. Dentro de las causas para su establecimiento, está la falta de capacidad económica, que como lo establece Flores Zavala, cuando nos dice: Pero la obligación de pagar impuestos, dijimos, empieza con la capacidad contributiva, no se le puede dispensar del cumplimiento de una obligación que no tiene ${ }^{27}$, asi como por sustitución de gravamen, para alimentos y bienes de consumo básico, servicios indispensables para la sociedad, asi como por razones de reciprocidad internacional y por actos del propio estado y sus bienes como los de dominio publico. De la Garza nos habla de las exenciones impropias, resulta de que a veces el legislador sigue el sistema de definir en forma negativa los hechos imponibles, o sea, el legislador excluye de la imposición determinadas circunstancias, no para exeptuarlas, sino para definir en forma negativa cuales son los hechos sometidos al impuesto $[\ldots]^{28}$, debiendo cuidar las palabras utilizadas como lo dice Carrasco Iriarte Si bien por subsidio debe entenderse el otorgamiento de beneficios de orden presupuestal y fiscal a las actividades económicas de los particulares, también es verdad que no se debe utilizar de tal forma que hagan nugatorio el mandato consitucional de prohibición de exención de impuestos ${ }^{29}$.

La propia Constitución en materia de impuestos municipales nos dice en el artículo 115 Contitucional fracción IV inciso c) segundo párrafo:

\footnotetext{
${ }^{24}$ Martínez LóPez, op. cit. nota 17, p. 64.

${ }^{25}$ Mabarak Cerecedo, op. cit. nota 18, p. 83.

${ }^{26}$ Tesis $2^{\text {a }}$ L/2012, Semanario Judicial de la Federación y su Gaceta, Tomo II, julio 2012, p. 1258.

${ }^{27}$ Flores Zavala, Ernesto (1990), Elementos de Finanzas Públicas Mexicanas, Porrúa, México, p. 193.

${ }^{28}$ De la Garza, Sergio Francisco (1981), Derecho Financiero Mexicano, $10^{\mathrm{a}}$ ed. México, Porrúa, p. 416.

${ }^{29}$ Carrasco Iriarte, Hugo (2010), Derecho Fiscal Constitucional, $5^{a}$ ed. México, Oxford, p. 135.
} 
Las Leyes Federales no limitarán la facultad de los Estados para establecer las contribuciones a que se refieren los incisos a) y c) ${ }^{30}$, ni concederan exenciones en relación con las mismas. Las leyes estatales no estableceran exenciones o subsidios en favor de persona o institución alguna respecto de dichas contribuciones. Sólo estarán exentos los bienes de dominio público de la Federación, de los Estados o los Municipios, salvo que tales bienes sean utilizados por entidades paraestatales o por particulares, bajo cualquier título, para fines administrativos o propósitos distintos a los de su objeto público.

La interpretación, forma parte de los principios fiscales, la aplicación a la norma fiscal para las exenciones es de modo estricto, aplicarse en sus términos y sin dar mas alcance que el que naturalmente tiene, por tanto la analogía no puede ser aplicada.

Así nuestra Ley de Hacienda para los municipios del Estado dice:

Articulo 5.- Las Normas de Derecho Tributario que establezcan cargas a los particulares y las que señalen excepciones a las mismas, serán de aplicación estricta. Se considera que establecen cargas a los particulares las normas que se refieren al sujeto, base, tasa o tarifa.

Las demás disposiciones fiscales se interpretarán aplicando cualquier método de interpretación jurídica.

\section{Impuestos municipales}

El municipio como entidad política, de acceso directo a las necesidades del pueblo, requiere de recursos para su desarrollo, pudiendo observar en nuestro entorno lo mencionado por parte de Rendón Huerta Barrera, cuando nos menciona que es patente el desarrollo, el estancamiento o la decadencia del municipio en razón de las finanzas con que cuenta y la forma de administrarlas ${ }^{31}$. Así encontramos municipios con pleno desarrollo y los que no cuentan en su gran mayoría de territorio de los servicios básicos, dependiendo de la administración, de las participaciones federales, pero también del apoyo que les pueda dar el Estado.

Haciendo un poco de historia encontramos que ni en el acta constitutiva, ni en la constitución de 1824 se hace alguna referencia al municipio, siendo hasta las siete leyes que constitucionalmente se consagró la existencia, organización y formas generales de funcionamiento para los ayuntamientos. En cuanto a la hacienda de los municipios nos dice Ma. Del Refugio Gonzalez, que la Ley de Desamortización de Bienes de las Corporaciones Civiles y Religiosas de 1856 asertó un duro golpe a los municipios del que no pudieron recobrarse en el resto del siglo ${ }^{32}$, lo anterior por considerarse como bienes de manos muertas a los bienes en administración de los municipios y comunidades indígenas, dejándose solo los edificios y terrenos destinados al servicio público de las poblaciones, así mismo nos refiere que aunado a la supresión por la constitución de 1857 de las aduanas interiores o alcabalas, de los que se beneficiaban los municipios, hizo caer sus fondos.

\footnotetext{
${ }^{30}$ Contribuciones sobre la propiedad inmobiliaria y los ingresos sobre la prestación de servicios a su cargo.

${ }^{31}$ Rendón Huerta Barrera, Teresita (1985), Derecho Municipal, México, Porrúa, p. 265.

${ }^{32}$ GonzÁlez, María Del Refugio (1987), "Debates sobre el Régimen del Municipio en México en el siglo XIX", en Estudios Municipales, México, Centro Nacional de Estudios Municipales Secretaría de Gobernación, p. 153.
} 
En el siglo XIX el llamado impuesto a la propiedad siempre fue polémico, primeramente por la tensión entre el gobierno central y los Estados para su cobro, aunado a la oposición de los terratenientes al catastro y a su pago. Ya para la epoca del Porfiriato los estados cobraban el impuesto, con la oposición de los propietarios y terratenientes; en tanto para 1922, siendo presidente Álvaro Obregón, trató de establecer el catastro federal y la creación del impuesto de uno al millar, que no pudo ser puesto en marcha por la oposición mencionada y también la de los Estados ${ }^{33}$.

La actividad económica en México se centra en zonas con beneficios como servicios, facilidad de transporte, educación, demanda comercial y recursos; lo que crea zonas de concentración económicamente rentables, y zonas atrasadas sin interés económico, que propicia la emigración con su respectiva contracción económica y mayor pobresa. Aunado a la falta de distribución de los recursos públicos, antes de la reforma de 1983, como lo explica Raúl Olmedo ${ }^{34}$ En 1982 el municipio recibe el más bajo porcentaje en la historia moderna de la distribución de los ingresos públicos: el 1\%. En 1929 -principio de la crisis mundial- recibía el $7.7 \%$; en 1932, el $8.9 \%$ (el máximo histórico); en 1940, el 5.3 $\%$; en 1950, el $3.3 \%$; en 1960 el $2.8 \%$; en 1970, el $1.6 \%$; en 1980, el 1.1\%., siendo el gobierno federal con sus gobiernos centralistas los que acaparan los recursos, dejando a los Estados el resto, con lo que se olvida a los municipios y sus necesidades.

El texto original de nuestra constitución de 1917 establecía en su fracción II Los municipios administrarán libremente su hacienda, las cual se formará de las contribuciones que señalen las Legislaturas de los Estados y que, en todo caso, serán las suficientes para atender a las necesidades municipales, siendo hasta la reforma impulsada por el presidente Miguel de la Madrid ${ }^{35}$, publicada el 3 de febrero de 1983, por la que se le dá, derecho constitucional a percibir contribuciones sobre la propiedad inmobiliaria, participaciones federales e ingresos por la prestación de servicios a su cargo. Reformas de las que indica, en ese momento, la maestra Teresita Rendón Huerta: a) no se concede un poder tributario al municipio, b) se asegura para el erario municipal las contribuciones inmobiliarias, siendo muy importantes, c) la prohibición de exentar o subsidiar abarca al municipio, y d) se hace necesaria la capacitación a funcionarios municipales para la programación del gasto publico. ${ }^{36}$

La Suprema Corte ha establecido los principios de la fracción IV del artículo 115 Contitucional como garantía de la autonomía municipal en la tesis en que actua como

\footnotetext{
${ }^{33}$ Unda Gutiérrez, Mónica y Moreno Jaimes, Carlos (2015), "La recaudación del impuesto predial en México: un análisis de sus determinantes económicos en el periodo 1969 -2010", Revista Mexicana de Ciencias Políticas y Sociales de la UNAM, México, núm 225, sep -dic. p. 53.

${ }^{34}$ Olmedo, Raúl (1985), El Desafio Municipal, México, Centro Nacional de Estudios Municipales, p. 13.

${ }^{35}$ En seguimiento a sus compromisos de campaña y de la reforma municipal el Ejecutivo Federal declara en la III reunión Nacional para la Evaluación de la Reforma Municipal,
La Reforma Municipal fue el reclamo del pueblo mexicano que, convencido de la validez permanente de esta tesis política de la Revolución Mexicana, la ha exigido junto con otros grandes cambios estruc- turales en nuestra vida política, social y económica, como una vía para ir por la ruta corta hacia la democracia, por la ruta del pueblo, por la ruta de las comunidades, haciendo participar a los ciuda- danos no solamente en el momento electoral, sino en las decisiones cotianas que afectan la vida social, no solamente en las decisiones, sino en su ejecución

en De La Madrid, Miguel (1987), "La Reforma Municipal Proyección hacia el Futuro", en: Estudios Municipales, México, Centro Nacional de Estudios Municipales Secretaría de Gobernación, p. 15.

${ }^{36}$ Ibídem, p. 272. 
ponente el Ministro José Ramón Cossío Días, en que los enumera: a) Principio de libre administración de la hacienda municipal, con su libre disposición y aplicación de sus recursos para la satisfacción de necesidades; b) Principio de ejercicio directo de su hacienda, sin sujeción alguna; c) Principio de integridad de los recursos municipales, para que reciban puntual, efectiva y completa tanto de las participaciones como las aportaciones federales; d) Derecho de los municipios a percibir las contribuciones sobre la propiedad inmobiliaria, de su fraccionamiento, división, consolidación, traslación y mejora, así como las que tengan por base el cambio de valor de los inmuebles; e) Principio de reserva de fuentes de ingresos municipales, para atender sus necesidades y responsabilidades; f) Facultad de las legislaturas estatales de establecer las cuotas y tarifas aplicables a sus contribuciones; y, g) la facultad de las legislaturas estatales para aprobar las leyes de ingresos de los municipios. ${ }^{37}$

Dentro de las limitaciones reales, que enfrentan los municipios para la recaudación de su principal impuesto inmobiliario, el predial, se encuentra la falta de cultura al pago de impuestos sobre lo que se tiene, las grandes areas rurales con sus predios rústicos y su bajo valor, incapacidad administrativa, falta de catastro actualizado y la historia de exención a tierras de ejido. Que por el contrario se identifica un potencial al ser un impuesto estable por la inamobilidad de los inmuebles y no estar sujetos a efectos económicos; la no resistencia en buenos gobiernos al reflejarse directamente en su comunidades; así como en ciudades con mayores necesidades de servicios y grado de urbanización en que se eleva el valor de los inmuebles, además de la recomendación en las reformas del año 2002, de equiparar el valor catastral al de mercado.

Actualmente la Ley de Hacienda para los Municipios del Estado de Guanajuato, establece en su Titulo Cuarto como impuestos: el predial, el de adquisición de bienes inmuebles, el de división y lotificación de inmuebles y el de fraccionamientos.

El impuesto predial se cobra por el hecho de ser propietarios o poseedores de un inmueble, por cualquier título, debiéndose de inscribir en el padrón fiscal municipal, siendo su base para su cobro el valor fiscal, con sus diferencias entre urbano, suburbano y rústico, así como a terrenos sin construcción, se deberá de pagar por anualidad o bimestral, existiendo cuota mínima para supuestos de apoyo definidos y con la obligación de manifestar cualquier cambio realizado al inmueble ${ }^{38}$.

El impuesto sobre adquisición de bienes inmuebles, anteriormente denominado sobre traslación de dominio, se causa por el hecho de adquirir un inmueble, conforme a la información realizada por el notario público que formaliza el acto, en el que establece los datos de operación, número de cuenta predial y catastral del inmueble registrado en el padrón municipal, y adjunta avaluo, tomandose como base el valor más alto entre el de operación, el registrado y el del avaluo ${ }^{39}$.

El maestro Javier Pérez Salazar en su artículo inconstitucionalidad del impuesto sobre adquisición de bienes inmuebles en el Estado de Guanajuato ${ }^{40}$, refiere la reforma

\footnotetext{
${ }^{37}$ Tesis 1a. CXI/2010, Semanario Judicial de la Federación y su Gaceta, novena época, Tomo XXXII, noviembre de 2010, p. 1213.

${ }^{38}$ Artículos 161 a 178 de la Ley de Hacienda para los Municipios del Estado de Guanajuato.

${ }^{39}$ Artículos 179 a 185 de la Ley de Hacienda para los Municipios del Estado de Guanajuato.

${ }^{40}$ Rendón Huerta Barrera, Teresita, Cervantes Herrera, José (Coords. 2016), “Inconstitucionalidad del
} 
a la ley de Hacienda para los municipios del Estado en que cambia el objeto pasivo del impuesto, pues anteriormente el artículo 179 establecía como obligado a este impuesto, la persona física o moral que transmite o adquiere por cualquier título o causa, bienes inmuebles. Para establecerse con la reforma que esta obligado a este impuesto, quien adquiere por cualquier causa bienes inmuebles, que con el fin de salvar la indefinición del objeto del impuesto, gravando el acto de adquisición con las mismas reglas, aplicando el valor más alto entre el registrado, el de avaluo y el de operación, refiriendonos que para el caso que se tome el avaluo estariamos reflejando la capacidad contributiva del adquirente, a diferencia si se toma el valor de operación que es la capacidad del enajenante, por lo que establece ante la falta de proporcionalidad la inconstitucional del artículo, debido a la falta legislativa ${ }^{41}$.

En cuanto al impuesto sobre división y lotificación, se aplica a los propietarios o poseedores de inmuebles que los dividan o lotifiquen, es decir que de una superficie mayor segreguen una parte, causándose sobre el valor de todo el inmueble, o para el caso de no división en los últimos dos años, sobre el valor de la superficie enajenada ${ }^{42}$

El de fraccionamientos es para aquellos que realicen divisiones en que establezcan calles, por lo que tendran mayores obligaciones como factibilidad de servicios, uso de suelo y servicios, entre otros en términos de la normativa ${ }^{43}$, como parte del proceso de autorización de un fraccionamiento ${ }^{44}$.

\section{Incongruencia en la interpretación conforme a nuestra constitución o inconstitucionalidad de los impuestos municipales sobre bienes inmuebles de servicios publico}

Al considerar a nuestra Constitución como el punto de partida de nuestro sistema jurídico, que reune los elementos y principios para en base a una forma de gobierno, división de poderes, estados soberanos, y facultades legislativas y de acción, sean estas leyes las que hagan coincidir sus valores hacia el bien común, que en términos de su artículo $133^{45}$, es la Ley Suprema de la Unión.

impuesto sobre adquisición de bienes inmuebles en el Estado de Guanajuato", en: Temas actuales de Notaría Pública obra conmemorativa de los 40 años de su especialidad, Universidad de Guanajuato División de Derecho, Política y Gobierno, México, p. 160.

${ }^{41}$ Ídem.

El proceso legislativo no motiva la propuesta de que sea el acto de adquisición el objeto a gravar, lo cual advierte un escenario de riesgo constitucional principalmente al sustentar la carga fiscal en relación al principio de proporcionalidad. Construír un impuesto de adquisición sobre un acto de enajenación, corre el riesgo de que se declare inconstitucional, ya que la capacidad contributiva se focaliza en el enajenante, una opción sería diseñar un impuesto de adquisición basado en la ausencia de contraprestación, tal y como lo regula el Impuesto sobre la Renta en el régimen de adquisición de bienes inmuebles.

${ }^{42}$ Artículos 186 a 191 de la Ley de Hacienda para los Municipios del Estado de Guanajuato.

${ }^{43}$ Código Territorial para el Estado y los Municipios de Guanajuato.

${ }^{44}$ Artículos 192 a 198 de la Ley de Hacienda para los Municipios del Estado de Guanajuato.

${ }^{45}$ Artículo 133 CPEUM, Esta Constitución, las leyes del Congreso de la Unión que emanen de ella y todos los tratados que estén de acuerdo con la misma, celebrados y que se celebren por el Presidente de la República, con aprobación del Senado, serán la Ley Suprema de toda la Unión. Los jueces de cada estado se arreglarán a dicha Constitución, leyes y tratados, a pesar de disposiciones en contrario que puedan haber en las Constituciones o leyes de los Estados. 
Tena Ramírez indica la obligación de cerciorarse que los actos esten apegados a la ley suprema y para el caso que se advierta que es inconstitucional se debe de enmendar, llamando defensa subsidiaria este ajuste, a lo dictado por nuestra Carta Magna, porque la principal interpretación y defensa está encomendada al Poder Judicial Federal ${ }^{46}$. Lo anterior aunado a la obligacion de los jueces en el articulo 133 y de los servidores públicos en general con su obligación de protestar la contitución y las leyes que de ella emanen ${ }^{47}$.

El cobro de los impuestos municipales están a cargo de las tesorerías u áreas especiales que establezca cada municipio, con personal con orientación al cobro e interpretación conforme a la Ley, bajo la amenaza constante del organo de fiscalización en sus revisiones. Siendo pocas las adquisiciones de bienes por parte del Estado, aplicando las mismas reglas y formatos administrativos que para los particulares.

Siendo materia de este artículo las adquisiciones realizadas por la Federación, los Estados o los Municipios respecto de bienes de dominio público, procederemos a revisar los impuestos inmobiliarios que les son aplicables.

En cuanto al cobro del impuesto predial en su artículo 161 de la Ley de Hacienda para los Municipios del Estado, se establece en su tercer párrafo, que están exentos los bienes de dominio público de la federación, del estado y de los municipios. Siendo conforme con el artículo 115 Contitucional fracción IV inciso c) segundo párrafo. No teniendo en lo general mayor problema en su interpretación y aplicación por parte de las áreas, dificultandose en algunas ocasiones la identificación en sus sistemas catastrales por no pagar impuestos y no actualizar su valor por parte del municipio.

Respecto del impuesto de adquisición de inmuebles, en el artículo 179 párrafo segundo de la Ley de Hacienda para los municipios del Estado, se indica que no se causará en adquisiciones realizadas para formar parte del dominio público de la federación, el estado o los municipios. Por lo que es conforme con el artículo 115 Contitucional fracción IV inciso c) segundo párrafo.

En tanto al impuesto de división, no se indica en forma expresa como en los anteriores, respecto a la exención o no pago para el caso que se adquiera como bien de dominio público, estableciendo los casos en que no se causa el impuesto en su artículo $187^{48}$. Por lo que a pesar de tener un artículo especifico para la exención, no se menciona que aplica lo

\footnotetext{
${ }^{46}[. .$.$] la Constitución debe ser la norma suprema de conducta de todos los poderes y de todos los fun-$ cionarios, en el orden federal y en el local. A ella deben ajustar sus actos todos, de suerte que antes de decidirlos deben cerciorarse que estén apegados a la ley suprema. TENA RAMírEz, Felipe (1976), Derecho Constitucional Mexicano, $14^{\mathrm{a}}$ ed. México, Porrúa, p. 562.

${ }^{47}$ Artículo 128 CPEUM, Todo funcionario público, sin excepción alguna, antes de tomar posesión de su encargo, prestará la protesta de guardar la Constitución y las leyes que de ella emanen.

${ }^{48}$ Artículo 187

No se causará este impuesto:

I.- Cuando los inmuebles sean adquiridos por herencia o legado;

II.- Cuando se trate de división de cosa común que haya permanecido en estado de indivisión durante tres años o más;

III.- Cuando la división de cosa común no tenga como resultado tipificar cualquiera de los supuestos legales sobre lotificación y fraccionamiento.
} 
establecido en nuestra constitución, respecto de los bienes inmuebles de dominio público, remitiendonos en su artículo $191^{49}$ de la misma ley, que para este impuesto se aplicarán las normas y plazos que se establece para el impuesto de adquisición, para su recaudación y control. Con lo que nos daría pauta a una interpretación, de si la norma que implica que no se causará para bienes de dominio público aplica para este impuesto ${ }^{50}$, atendiendo a la falta de claridad por una irregularidad en su redacción, que para no ser repetitivo se va a las normas del impuesto anterior, considerando los fines del acto de adquisición. Caso contrario de lo que contiene la regla del artículo 5 de la misma Ley, que refiere que en cuanto a las cargas a los particulares y las excepciones a estas, serán de aplicación estricta. Por lo que al dejar de establecer en forma expresa la exención o el no pago del impuesto de división, es contrario a lo establecido por el artículo 115 Contitucional fracción IV inciso c) segundo párrafo.

Este impuesto de división por la similitud de conceptos es confundido con el trámite previo necesario conforme a nuestra normas urbanisticas, el permiso de división, que se otorga cuando existe factibilidad de servicios, superficies, uso de suelo y conforme a los planes de desarrollo municipal para hacer dos predios distintos, previo pago de derechos por el actuar administrativo municipal. Tal permiso de división es requisito necesario para formalizar un acto que conlleve tal división. Si bien es cierto que el causante o sujeto del impuesto de división conforme a la Ley actual es él que divida, tambien lo es que dicho impuesto no tiene razón de ser, primeramente porque el acto de división implica acciones administrativas que pudieran configurarse en un derecho, por la apertura de la nueva cuenta catastral, la identificación del predio restante. Lo anterior, porque el acto de traslación ya está establecido en el otro impuesto de adquisición, por el que se cambia de titular el bien, configurandose el impuesto sobre la tenencia de inmuebles al nuevo propietario o poseedor al registrarlo para el pago de predial, que es el impuesto base. Así el legislador local al identificar en el inciso a) del artículo 115 Contitucional, la división como parte de las contribuciones facultadas al municipio, lo estableció como impuesto, debiendo de haberlo hecho en el apartado de derechos que tambien son contribuciones, por la naturaleza de las acciones administrativas que realiza, habiendo cobrado el impuesto de adquisición que esta soportado en la capacidad contributiva del patrimonio que se adquiere.

En la mayoría de los casos los municipios aceptan la exención de todos los impuestos en la adquisición del Estado para bienes de dominio público, interpretando que la propia constitución establece dicha figura, la subsidiariedad de aplicación de las normas del impuesto de adquisición que expresamene lo establece. Así como con el elemento de beneficio directo que tendra el municipio con la prestación de servicios publicos a cargo del Estado, e incluso en muchos de los casos participando con el acto de adquisición, que para el caso de donantes, participará con parte de su terreno, por el que no estaría de acuerdo en pagar un impuesto ademas de su aportación.

49 Artículo 191.- Para la recaudación y Control del impuesto serán aplicables las normas y plazos que para el pago del impuesto de adquisición se estable en la presente Ley.

50 Tesis $2^{\mathrm{a}}$./J. 26/2006, Semanario Judicial de la Federación y su Gaceta, Novena Época, Tomo XXIII, marzo de 2006, pág. 250, "LEYES. SU INCONSTITUCIONALIDAD NO DEPENDE DE LOS VICIOS EN LA REDACCIÓN E IMPRESICIÓN DE TÉRMINOS EN QUE EL LEGISLADOR ORDINARIO PUEDA INCURRIR. 


\section{A manera de conclusión}

El Estado en sus tres ordenes de gobierno: Federal, Estatal y Municipal, tiene como encargo, la prestación de servicios públicos a la ciudadanía, por lo que deberá tener bienes que se denominan de dominio público por estar destinados a esos fines, y con recursos obtenidos de los impuestos.

Nuestra Constitución en su artículo 115 fracción IV, le otorga a los municipios la atribución de cobro respecto de los impuestos inmobiliarios de su adscripción, estableciendo principios y lineamientos para que por medio de su legislación local, se determinen sus elementos, sujetos, plazos, bases, tasas y exenciones, que tendrán que seguir los principios de legalidad y proporcionalidad para hacer generales sus determinaciones, con el fin de que se hagan de recursos propios para sus funciones.

A manera de coherencia respecto del destino de los impuestos, y ser bienes que el propio Estado utiliza en forma directa para la prestación de los servicios públicos, se establece a nivel constitucional que se encuentran exentos de los impuestos inmobiliarios, aquellos inmuebles destinados al dominio publico de la Federación, los Estados o los municipios. Por lo que conforme a nuestro sistema de congruencia Constitucional, toda ley debe de estar en línea a nuestra Carta Magna, siendo la base que faculta a la Ley de Hacienda para los Municipios del Estado, para que se establezcan los impuestos sobre los bienes inmuebles. Así mismo, debe de atender los casos de exención que establece la norma magna, como expresamente se contiene en el impuesto predial y en el impuesto de adquisición, no siendo asi en el impuesto de división, que a pesar de que tiene un articulo para aquellos actos que no causan este impuesto, no se contempla lo relativo a los bienes de dominio público.

El articulo 115 fracción IV inciso c) segundo párrafo, indica la exención de contribuciones respecto de bienes del dominio publico de la Federación, de los Estados y de los municipios, expresamente hace referencia a los mencionados en el inciso a) de la misma fracción "sobre la propiedad inmobiliaria, de su fraccionamiento, división, consolidación, traslación y mejora así como las que tengan por base el cambio de valor de los inmuebles", por lo que la Ley de Hacienda para los Municipios del Estado al no contemplar dicha exención en el impuesto de división, es en estricto sentido inconstitucional.

La finalidad de los impuestos, es que el estado conforme a sus atribuciones preste los servicios públicos que les son encomendados, existiendo la posibilidad por los particulares, de contribuir de manera libre y gratuita con las acciones y bienes para el beneficio de su comunidad. Por lo que si los bienes aportados son utilizados o son con la finalidad de la prestación de un servicio público, se considera justo considerar exento de todo impuesto el acto de enajenación gratuita, de bienes destinados a formar parte del dominio público del Estado.

La inconstitucionalidad de la Ley de Hacienda para los Municipios del Estado, en cuanto al impuesto de división, quedaría subsanada si se establece en forma expresa en la ley, que igualmente que en los otros impuestos inmobiliarios, se esta exento de pago para el caso que de sea un inmueble que pasará a formar parte del dominio público.

Por lo que al existir un artículo respecto del impuesto de división, que contiene las causales autorizadas para su no pago, se considera que es el espacio adecuado para su establecimiento, adicionando una fracción más al artículo 187, como fracción $I V$, que 
establezca que no se causa dicho impuesto: Cuando los inmuebles sean adquiridos por la Federación, el Estado o los Municipios para formar parte del dominio público.

Por lo que quedaría de la siguiente forma:

Artículo 187.- No se causará este impuesto:

I.- Cuando los inmuebles sean adquiridos por herencia o legado;

II.- Cuando se trate de división de cosa común que haya permanecido en estado de indivisión durante tres años o más;

III.- Cuando la división de cosa común no tenga como resultado tipificar cualquiera de los supuestos legales sobre lotificación y fraccionamiento."

IV.- Cuando los inmuebles sean adquiridos por la Federación, el Estado o los Municipios para formar parte del dominio público.

Siguiendo la redacción del artículo 115 fracción IV inciso c), que establece la exención de impuestos a los inmuebles del dominio público de la Federación, los Estados y los Municipios, que indica en su parte final, que: "salvo que tales bienes sean utilizados por entidades paraestatales o por particulares, bajo cualquier titulo, para fines administrativos o propósitos distintos a los de su objeto público", en virtud de que el impuesto de división se causa únicamente en el acto de adquisición, por lo que no se considera oportuno agregar la salvedad constitucional respecto de su utilización, que sí aplica y se contiene para el caso del impuesto predial, que es de uso continuo, y para el impuesto de división, se establece que son solo aquellos bienes destinados a formar parte del dominio público, a diferencia de aquellos destinados para su uso privado o un fin distinto de su objeto público. Habiéndose definido en la Ley del patrimonio inmobiliario del Estado y la Constitución local los bienes que se consideran de dominio público para su puntualización.

\section{Fuentes de información}

\section{Bibliográficas}

Arce y Cervanates, José (2008), De los Bienes, $7^{\mathrm{a}}$ ed. México, Porrúa.

Carrasco Iriarte, Hugo (2010), Derecho Fiscal Constitucional, $5^{\text {a }}$ ed. México, Oxford.

De Ibarrola, Antonio (1957), Cosas y Sucesiones, México, Porrúa.

De la Garza, Sergio Francisco (1981), Derecho Financiero Mexicano, 10 a ed. México, Porrúa.

De la Madrid, Miguel (1987), "Proyección hacia el Futuro", en: Estudios Municipales, México, Centro Nacional de Estudios Municipales Secretaría de Gobernación.

Delgadillo GutiérRez, Luis Humberto y LUCERO ESPINOSA, Manuel (2008), Compendio de Derecho Administrativo, segundo curso, $4^{\mathrm{a}}$ ed. México, Porrúa.

Fraga, Gabino (2003), Derecho Administrativo, 43ª ed. México, Porrúa.

Galindo Garfias, Ignacio (1993), Código Civil para el Distrito Federal en materia común y para toda la República en materia federal comentado, $2^{\mathrm{a}}$ ed. México, Grupo Editorial Miguel Ángel Porrúa-UNAM, t. II. 
GonzÁlez, María Del Refugio (1987), "Debates sobre el Régimen del Municipio en México en el siglo XIX”, en: Estudios Municipales, México, Centro Nacional de Estudios Municipales Secretaría de Gobernación.

Mabarak Cerecedo, Doricela (2007), Derecho Financiero Público, $3^{\mathrm{a}}$ ed. México, McGRaw-Hill Interamericana.

Martínez López, Luis (1959), Derecho Fiscal Mexicano, México, Porrúa.

Olmedo, Raúl (1985), El Desafio Municipal, México, Centro Nacional de Estudios Municipales Secretaría de Gobernación.

Rendón Huerta Barrera, Teresita (1985), Derecho Municipal, México, Porrúa.

y Cervantes Herrera, José (coords., 2016), "Inconstitucionalidad del impuesto sobre adquisición de bienes inmuebles en el Estado de Guanajuato", Temas actuales actuales de Notaría Pública obra conmemorativa de los 40 años de su especialidad, México, Universidad de Guanajuato División de Derecho, Política y Gobierno Departamento de Derecho.

Reyes Tayabas, Jorge (1993), Derecho Constitucional aplicado a la Especialización en Amparo, $2^{\mathrm{a}}$ ed. México, Themis.

Rojas Caballero, Ariel Alberto (2009), Las Garantias Individuales en México, $4^{\mathrm{a}}$ ed. Porrúa, 2009.

Sánchez Gómez, Narciso (2015), Segundo Curso de Derecho Administrativo, $5^{\mathrm{a}}$ ed. México, Porrúa.

\section{Legislación}

Código Civil para el Estado de Guanajuato.

Constitución Política de los Estados Unidos Mexicanos.

Constitución Política del Estado de Guanajuato.

Ley del Patrimonio Inmobiliario del Estado.

Ley de Hacienda para los municipios del Estado de Guanajuato.

Lineamientos de Control Patrimonial de la Secretaría de Finanzas, Inversión y Administración.

Código Territorial para el Estado y los Municipios de Guanajuato.

\section{Jurisprudencia}

Tesis $1^{\text {a }} \mathrm{CXI} / 2010$, Semanario Judicial de la Federación y su Gaceta, $9^{\mathrm{a}}$ época, tomo XXXII, noviembre de 2010, pág. 1213.

Tesis 641, Semanario Judicial de la Federación y su Gaceta, séptima época, Tomo I, pág. 1787.

Tesis $2^{\mathrm{a}}$ L/2012, Semanario Judicial de la Federación y su Gaceta, Tomo II, julio 2012, pág. 1258. 
Tesis 1a. CXI/2010, Semanario Judicial de la Federación y su Gaceta, novena época, Tomo XXXII, noviembre de 2010, pág. 1213.

Tesis $2^{\mathrm{a}}$.J. 26/2006, Semanario Judicial de la Federación y su Gaceta, Novena Época, Tomo XXIII, marzo de 2006, pág. 250. 